Article

\title{
Decision Support Systems for Water Resources Management in Developing Countries: Learning from Experiences in Africa
}

\section{Carlo Giupponi $^{1, *}$ and Alessandra Sgobbi ${ }^{2}$}

1 Department of Economics and Euro-Mediterranean Centre for Climate Change (CMCC), Ca' Foscari University of Venice, San Giobbe 873, Venezia 30121, Italy

2 United Nations Economic Commission for Africa, P.O. Box 3005, Addis Ababa, Ethiopia; E-Mail: asgobbi@uneca.org

* Author to whom correspondence should be addressed; E-Mail: cgiupponi@unive.it; Tel.: +39-041-234-9126; Fax: +39-041-234-9176.

Received: 18 April 2013; in revised form: 24 May 2013 / Accepted: 27 May 2013 /

Published: 19 June 2013

\begin{abstract}
Decision support system (DSS) tools are rather popular in the literature on water resources management. The European Project "Splash" conducted a survey of the literature and of DSS implementation in developing countries with specific reference on Africa. Experts in the field were consulted through an ad hoc questionnaire and interviews. The results of the survey indicate that the exchange of experiences amongst projects with similar objectives or even the same case study is very limited, with a tendency towards restarting every time from scratch. As a consequence, it seems that DSS developments have produced only limited positive impacts. Most experts contacted shared either the frustration deriving from the limited impacts on intended end-users, who rarely used the tool after the project end, or in the case of ongoing projects, the preoccupation for future maintenance. Responses from the questionnaires indicate that priority efforts should not focus on developing the tools, but rather on improving the effectiveness and applicability of integrated water resource management legislative and planning frameworks, training and capacity building, networking and cooperation, harmonization of transnational data infrastructures and, very importantly, learning from past experiences and adopting enhanced protocols for DSS development.
\end{abstract}

Keywords: decision support system; water resources management; developing countries; Africa 


\section{Introduction}

In recent years, the management of natural resources has become an increasingly challenging issue for several reasons. First of all, the problems themselves are characterized by intrinsic complexity as a consequence of the complex spatial and temporal features of water and related ecosystems. This is particularly true for ecosystems in which natural drivers interact with evolving human activities, within the context of what is often defined as the social-ecological system or simply socio-ecosystem [1]. Secondly, environmental issues are always the object of diversified, and often conflicting, interests (economic, social, cultural ones). As the general public has shown increasing attention for environmental matters, groups and individual citizens are becoming important actors in planning and decision-making processes, further complicating the problem. Thirdly, knowledge about socio-ecosystems is often fragmented and owned by a multitude of experts, practitioners and stakeholders. Finally, environmental policies and regulations, from local to international, have become more articulated and complex, calling for strengthened support from scientifically robust methods and tools to assist managers and policy makers.

The complexities inherent in the management of natural resources require the integration of scientific knowledge and economics with social problems, such as conflict management, the settlement of disputes and the mitigation of divergent interests and values. However, competing values and contradictory beliefs increasingly dominate the policy-making discourses, as different scientific disciplines are not always able to give unambiguous responses to complex issues, such as climate change, biodiversity loss and environment-related diseases. Furthermore, fundamental uncertainties and the risk of irreversible environmental changes make natural resources management an even more challenging task, giving rise to different perspectives about the problems, their policy implications and possible solutions. For these reasons, decision problems related to the management of natural resources are often defined as "wicked" problems, characterized by contradictory identification and multiple definitions, possible interpretations and solutions [2].

The current situation requires new or improved integrated approaches in which the knowledge of diverse disciplines is combined in a unified methodological and operational framework [3], with adequate management and communication of uncertainty and with a persistent involvement of decision makers and stakeholders and consideration of their views [4-6].

The research community is asked to develop and transfer methodological approaches, which can support the implementation of transparent planning/management processes to meet policy/decision makers' requirements and achieve more robust and informed decisions [4]. The "traditional" knowledge in physical/environmental sciences must thus be integrated with sound economic methods, but also with methods borrowed and adapted from sociology, information and communication sciences and other disciplines [7-12]. In particular, significant improvements can come from the innovative methods for structured integration of methodological and operational approaches pertaining to three different disciplines: simulation modelling (SM), participatory planning (PP) and decision analysis (DA). There is a vast literature focusing on each of these three disciplines (see, for instance, $[13,14]$ on SM, [15-17] on PP and [18] on DA), promoting various methodological approaches to tackle complex environmental problems; yet, each of the proposed approaches is prone to flaws and shortcomings, which may have significant impacts on the final results of the policy, planning or decision-making 
processes, ultimately determining their success or failure. However, accepting the challenge of combining the three methodological approaches in an integrated framework can provide an opportunity to effectively exploit their full potentials in improving natural resources management.

Integrated water resource management (IWRM) is a paradigmatic case in which simulation models, participatory planning and decision analysis can be effectively integrated to deliver robust methods and tools in support of planning and implementing the principles of sustainable IWRM:

- (1) SM embodies the disciplinary scientific knowledge of phenomena, physical or otherwise, and as such, is crucial in analyzing socio-ecosystems for their sustainable management [19]. It can be useful to explore and project into the future the effects of (new) policies or of other drivers, such as climate change. With adequate interfaces, SM may support communication between the various disciplinary experts and with a broader public of interested people [12], also within the process of making decisions $[13,14]$.

- (2) At the heart of the PP paradigm is the will to balance the rights of majorities and minorities in public decisions and the belief that inefficient policies and practices in environmental management are often a consequence of top-down approaches, failing to integrate stakeholders' concerns, aspirations and constraints [20]. The participation of multiple actors (stakeholders in a broad sense or experts of different disciplines) is a common feature of IWRM and a prescription of water-related legislation worldwide. It is thus crucial to adopt tools that enable the adequate management of their contributions to the decision/policy-making (D/PM) process.

- (3) DA encompasses methods and reference frameworks to structure decision problems, generate, elicit and aggregate preferences (value judgments) on different aspects of pursued polices [21-23]. DA plays a fundamental role when problems are complex and dynamic, such as the case of IWRM, and when robustness and transparency is required for mitigating the biases caused by humans' limited capacity to compare multi-dimensional problems and possible solutions and make trade-offs between costs and benefits explicit and manageable [24,25].

Decision and information support tools (DISTs) offer promising opportunities for the integration of different disciplines and methodologies in support of decision-making processes and, in particular, by providing the methodological and operational framework to integrate SM, PP and DA. DISTs, as a broad category of computerized instruments, can facilitate the transfer of skills and methods for structuring and exploring problems and the generation of information for analyzing and supporting decisions [26]. Examples of DISTs are geographical information systems [7,27,28], integrated assessment and modelling [10-12,29-32] and decision support systems (DSSs) [6,26,33-37].

DSS tools target, specifically, the interface between science and practitioners, thus proving operational solutions to support policy makers in dealing with complex environmental problems of the socio-ecosystem at various scales. In addition to the core functions targeting decision analysis, they usually include capabilities for modelling and, in some cases, also for the management of participatory processes. Such DSS tools can provide the operational framework for the integration of SM, PP and DA methodologies and approaches.

DSS tools, which integrate those three dimensions, can thus provide operational solutions for the decision process in its entirety. Firstly, they provide a framework for the organization of information and knowledge (multi-source spatial and temporal data) and their elaboration with a variety of 
simulation models and elaboration procedures [5]. Secondly, they support policy/decision makers in the assessment of plausible management strategies, by means of decision analysis procedures and algorithms. Thirdly, they facilitate transparent and scientifically sound management of participation, by providing procedures for the analysis of social networks, individuals' preferences, priorities and value judgments.

Numerous solutions can be proposed for the integration of the required disciplinary components, which should be framed within methodological frameworks that consider all the phases of the policy- or decision-making processes. With such an approach, integrated operational solutions are provided for participatory planning, simulation modelling and decision analysis, as proposed in Figure 1.

Figure 1. A generic decision/policy-making process, with its main steps and the areas of influence of participatory planning, simulation modelling and decision analysis.

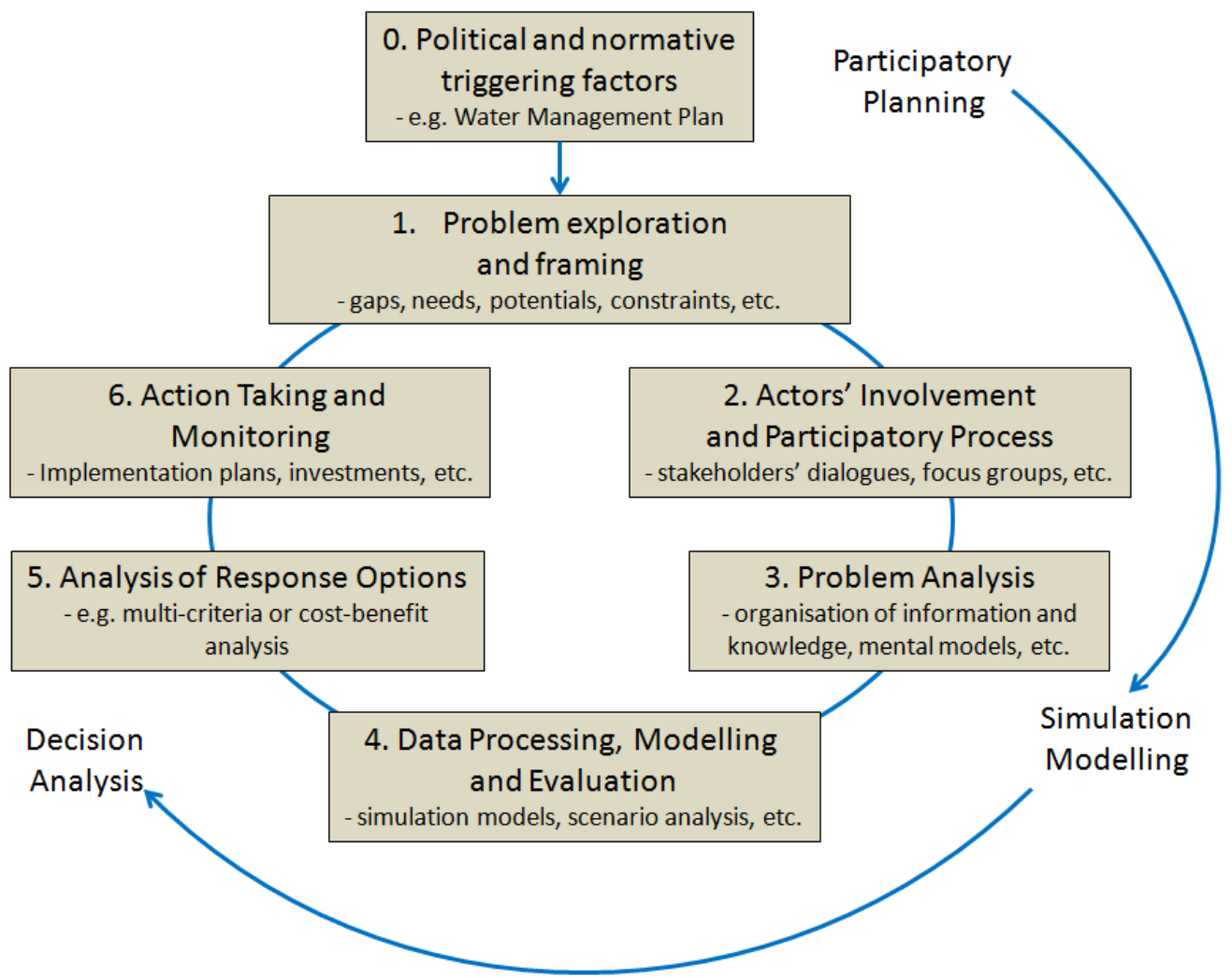

Having the proposed methodological framework in mind, the Splash Project (Coordinating European Water Research for Poverty Reduction; funded by the European Commission under Framework Program 6 [38]) included in its activities a survey on "Using modern decision support systems for evidence-based policy-making in integrated water resources management (IWRM) in developing countries", with a general objective to harness the potential of modern decision support systems for policy and decision-making in the field of IWRM in developing countries. More specific objectives of the survey were to assess how much of the proposed framework can be found or not in recent implementations of DSS tools and how much this can be related to cases of success or failure with a geographical focus on Africa.

The survey was conducted on available scientific literature, but also as far as possible on "grey" references (reports and other documents not published on refereed journals, but available for download 
from the Internet) and through contributions from experts involved in relevant recent projects, by means of an ad hoc questionnaire, email contacts and phone conversations. Experiences were collected, in particular, with reference to three large geographical areas: Eastern (the Nile River Basin), Western (the Volta River Basin) and Southern Africa.

This paper reports the results of the Splash survey, analyzed and discussed with reference to the proposed methodological framework, aiming at contributing to future developments in the field and at increasing the potential for broader adoption of DSS tools by potential end-users: other researchers, professionals and consultants, as well as decision makers. In the following section, the methodological background is provided, including both what emerges from the literature and from the survey conducted. Section 3 presents the results of the survey, while concluding remarks and recommendations are reported in Section 4.

\section{Decision Processes and Water Resources Management}

Traditionally, modelling in IWRM is seen as a method for simulating the various components of the system under examination (e.g., a river basin) through a mathematical formalization of reality. This approach usually concentrated on physical and ecological processes, such as biogeochemical or water balances [29], while the social and economic dimensions were often not included, as they are more difficult to quantify or formalize.

In recent times, however, the role of modelling in IWRM and the definition of "models" itself have become more encompassing. For instance, according to Hare, in the field of water resources management, models should be intended "broadly, to consider both what they represent in the river basin (e.g., run-off, population change, stakeholder perceptions) and how they may be packaged for use" [30]. The more the social and economic dimensions gain relevance in IWRM, the more the modelling theory and practice expand to include soft science approaches, such as mental models. These are used to provide an "internal", subjective representation of reality, which can be made explicit (i.e., "external") by means of cognitive maps and similar forms of communication [15]. External representations of mental models can then be used as the basis for developing or selecting suitable mathematical models, with much stronger potential for understanding and uptake by actors involved in the $\mathrm{D} / \mathrm{PM}$ process.

Cognitive mapping techniques have, then, a crucial role to play in ensuring that the emerging external model(s) provide(s) an accurate enough representation of internal structures and beliefs, as well as a good enough compromise view of the problem under discussion, thus representing a fundamental intermediate step of participatory modelling and decision-making [6].

The idea of participatory approaches in decision processes per se is not new: its origin in the field of environmental management and sustainable development is traditionally traced back to Agenda 21 [39], which identified "information", "integration" and "participation" as key factors for the achievement of sustainable development [40]. Since then, the role of public participation has been reinforced in many international conventions and national or regional policies [16].

The rationale underlying public participation in decision-making is simple and intuitive: the "public" is more likely to accept a policy when it is consulted beforehand or when it takes active part in its definition. The proponents of the PP paradigm assert that concerted decisions can lead to 
management choices, which are better adapted to local conditions, are easier to implement and less likely to cause or exacerbate conflicts and instabilities. Participatory approaches are believed to improve decision-making (both outcome and processes), by encouraging dialog and promoting a shared understanding of the problem.

A variety of methodologies for public participation have been developed and potentially useful for environmental management [17], ranging from unilateral information from government to the general public, to various forms of direct or indirect involvement of stakeholders in the deliberations [41].

Participatory approaches, however, may not always lead to the expected improvements [42]. In some cases, the competent authority may not be ready to hand over part of its decision-making mandate. Linked to the issue of power management is that of representation: who should take part in the process is not clearly defined, nor are there agreed upon mechanisms to help select among stakeholders-individuals or groups [27].

PP remains, nonetheless, another necessary component of D/PM in IWRM, and thus, it should find adequate methodological and operational support, in particular for what concerns participatory model building and group decision-making, which should involve, along with experts, the stakeholders affected by the decisions for which the models are intended. The process of participatory modelling can then be formulated as a sequence of steps that, besides the exploration and formalization of the problem, start with the identification of the actors to be involved, the organization of activities, such as interviews or workshops for the development of shared mental models, to be further developed in operational management models, in support of decision analysis.

D/PM in IWRM usually features the choice within a set of plausible alternative solutions, and thus, DA should support scientifically sound, technically robust and unbiased judgments by the decision makers. As IWRM is characterized by conflicting interests and beliefs, consensus and compromise seeking are usually basic requirements of D/PM processes.

Preferences of stakeholders need to be elicited first and contrasted with the stated objectives in order to describe how well they may be satisfied by plausible solutions under examination.

Methods for decision analysis of interest for IWRM are too numerous to mention, ranging from different approaches based on monetary valuation, such as cost benefit analysis (CBA), utility theory, to Bayesian belief networks. Multi-criteria analysis methods (MCAM) [21], have gained credibility in the field of IWRM, thanks to their ability to overcome the human limits to intuitively combine different sources of information in a rational way, without requiring the estimation of monetary values as required, for instance, by CBA. Decision makers can find support in the vastest MCAM literature for organizing and synthesizing complex and conflicting multidimensional features of the issue analyzed, thus improving their ability to explore and assess trade-offs between alternative options and stakeholders' preferences, but adequate tools are needed to support the practical implementation of available methods [35].

In a context in which multiple actors are involved in the decision process, DSS tools providing operational MCAM can significantly contribute by making explicit conflicting values and individual preferences, thus facilitating decision makers to interactively examine the tradeoffs between objectives and to aggregate individual preferences. However, there are also evident limitations and flaws. For example, the use of different techniques may indeed lead to contrasting results, even when applied to the same datasets. Therefore, adequate training and documentation is needed. 
The methodological issues discussed so far and their solutions are, to some extent, complementary. Well-designed participatory processes and DSS tools create positive conditions for predictive models being understood and trusted. Models that reflect needs and governing drivers of policy-making are more likely to yield reliable and socially robust knowledge, which in turn, increases the prospects for policy success. Taking advantage of these achievements, decision analysis can help all actors to understand (and represent in explicit form) values and negotiate divergent interests to seek compromise.

A combination of predictive, mathematical modelling with methodologies to analyze policy problems (such as cognitive mapping) can surface and incorporate contextual (local) knowledge and improve the suitability and applicability of models to the policy problem. Scientifically sound techniques based upon a combination of PP, SM and DA, transparent and flexible enough to fit the specific needs, may have a positive impact on the commitment of policy makers, and well-structured participatory processes may preserve their commitment during the whole policy-making and implementation progress. The proper use of DISTs should aim at improving the quality of the D/PM process, facilitating decision makers' reflections, explorations of preferences and conflicts, raising awareness and commitment of stakeholders, etc., while the provision of the final or optimal solution for the given problem (i.e., the decision itself) should be out of consideration.

In such a complex framework, Decision Support Systems (DSS) attract the attention of policy makers as potentially effective tools in support of water resources management, with a specific role to be played for the integration of the multiple disciplinary components, while considering multiple objectives. For brevity, that specific category of DSS tools is named below as "IWRM-DSS". Therefore, the IWRM acronym is used in this paper as a concise term expressing the ambition to cope with those needs, without any reference to the interpretations given by specific authors or organizations.

After this rather concise introduction to the state of the art of decision support in the environmental field, and IWRM in particular, expectations about the role of DSS tools in the current practice of IWRM could be very high. On the contrary, notwithstanding the great potential, experience shows that the uptake of DSSs, even when they are freely downloadable, adequately documented, etc., is very limited in practice outside the research community [5]. Several reasons for this can be found in the international literature, such as the need to frame computerized tools within the decision management practices adopted by practitioners, thus requiring a methodological framework adapted to local institutional, procedural and cultural settings. Given the relevance and the magnitude of IWRM issues in developing countries and, in particular, in the African continent, it appeared of greatest interest for the Splash project to investigate the state-of-the-art in the field and propose possible directions to improve the current situation.

Googling for IWRM-DSS produced 13,100 results on February 2013, while searching for scientific publications with the keywords DSS and water in the title, keywords or abstract produced more than 3000 results on Scopus [43], with an evident increase in number papers over the last 20 years. These few data are emblematic for understanding that the DSS research and literature are very active in the field of water resources. One issue requiring careful consideration in such an applied field is the relative richness of "grey" references in particular (project reports, working papers, web pages, etc.), which report on operational implementations and demonstration projects. The scientific literature of refereed journals instead is relatively poor of application cases, and it usually presents methods and prototypes. Setting up links between these two main sources of information was one of the challenges 
of this work. Knowing about the fate of prototypes presented in scientific journal is a typical challenge, which limits the possibility of assessing the success of the many projects having the development of DSS tools within their objectives. For this reasons, direct contacts with international organizations and experts in developing countries have been set up with the support of an ad hoc questionnaire.

Direct information about the state of the art of IWRM-DSS applications in Africa was collected through a questionnaire circulated to experts identified in the international literature and through the Splash Scientific Advisory Board. The questionnaire (reported in the supplementary to this article) was divided into five sections: (a) identification of the respondents; (b) opportunities and barriers in using IWRM-DSS for policy/decision-making (identified strengths and weaknesses, direction to overcome them and medium-/long-term perspectives); (c) reaction to a proposed check list to guide DSS development and implementation and identification of the most critical issues for more effective IWRM-DSSs; (d) proposed roadmap for promotion, application and improvement of IWRM-DSS (current perspectives in developing countries, constrains to wider use, most urgent needs, investments required besides innovative research, the key actors and the training and capacity building issues); and (e) further suggestions.

Having identified the area of greater geographical interest, three questionnaires were compiled with reference to the Nile River Basin (Guido Santini, FAO, Rome, Italy; Abdulkarim H. Seid, Nile Basin Initiative, Addis Ababa, Ethiopia; and Henrik R. Sørensen, DHI, Copenhagen, Denmark); one referred to the Volta River (Frank Ohene Annor, Kwame Nkrumah University, Ouagadougou, Burkina Faso), one to South Africa (Jean Marc Mwenge Kahinda, Council for Scientific and industrial Research, Pretoria, South Africa) and three with general reference to the continent (Matthew McCartney and Parvaneh Honarmand, International Water Management Institute, Battaramulla, Sri Lanka; and Olivier Cogels, freelance consultant, Dakar, Senegal).

The following section presents the results of the survey on IWRM-DSS implementation in Africa, with the aim of comparing the evidence emerging from recent experiences there, with those found in the international literature introduced above and proposing solutions to improve the current situation and the development of future IWRM-DSS tools and applications.

\section{The Splash Survey}

It is worth initiating this section with focus on Africa by mentioning a DSS focused on the African continent, which is not, in fact, a true DSS according to the usual meaning of the acronym and the definitions provided above. The Data Synthesis System for World Water Resources is an initiative of the World Water Assessment Program of the International Hydrological Program of the United Nations Education Scientific and Cultural Organization (UNESCO/IHP), which provides a web-based geographical information system for water resource assessment (see homepage in Figure 2). The system stores and makes available to interested users spatial and statistical point- and grid-based socioeconomic and biogeophysical data organized according to a river basin base map and a series of thematic indicator layers. 
Figure 2. The Data Synthesis System (DSS) for World Water Resources [44].

\section{Data Synthesis System for World Water Resources}

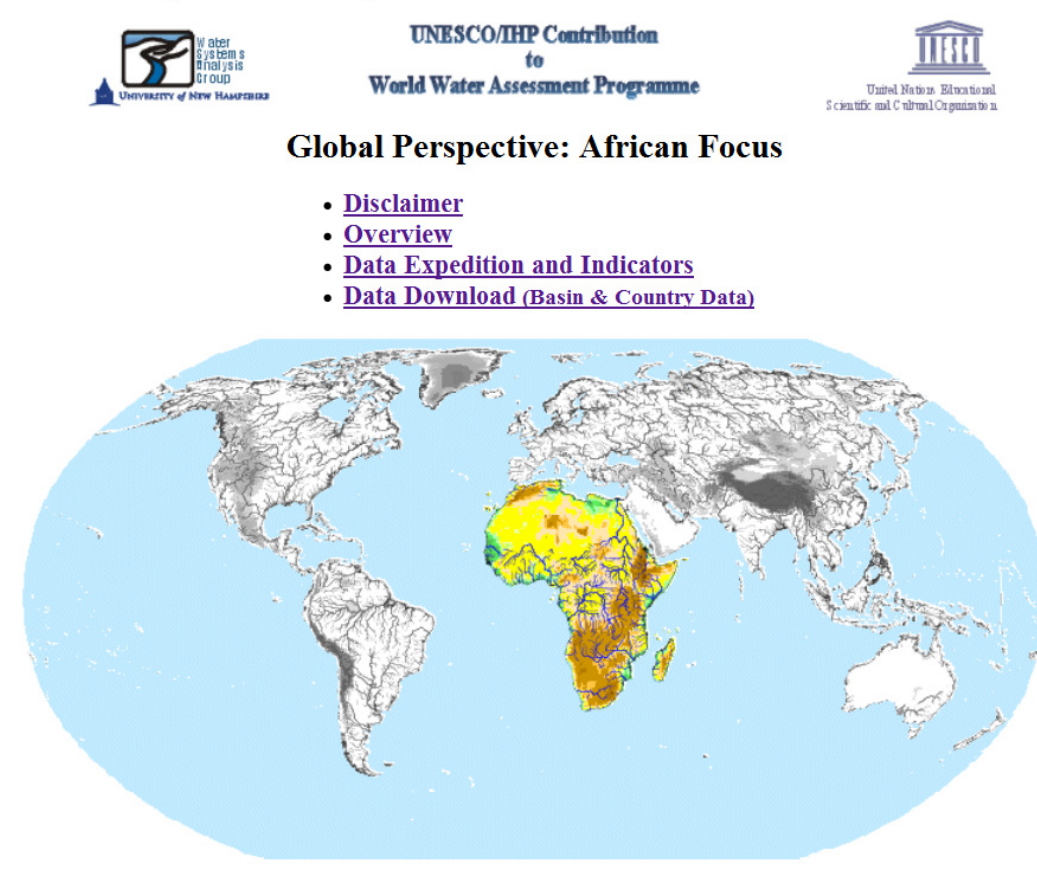

(c) Copyright: United Nations Educational, Scientific and Cultural Organization. All rights reserved Contact e-mail at $\underline{\mathrm{UNESCO} / \mathrm{IHP}}$ and $\underline{\mathrm{UNH}}$

This initiative is an attempt to cope with one of the most frequently cited critical issues affecting the effectiveness of IWRM-DSS tools in Africa, notably, the limited availability of data, together with the duplications of efforts to solve it.

The readers are invited to take advantage of the information provided by the Data Synthesis System for concise introductions to the main geographical features of the three areas treated below: Western Africa and, in particular, the Volta River Basin, the Nile River Basin in the east and Southern Africa and, in particular, the Orange River Basin.

\subsection{East Africa (Nile River Basin)}

The $6850 \mathrm{~km}$-long Nile is the world's longest river. Its basin covers about $10 \%$ of Africa (approximately $3 \mathrm{M} \mathrm{km}^{2}$ ), and it is spread over eleven countries (Burundi, Congo, Egypt, Eritrea, Ethiopia, Kenya, South Sudan, Sudan, Tanzania, Uganda and Rwanda). Very importantly, almost all the Nile water flow is generated from rainfall on an area covering only $20 \%$ of the basin (the rest being arid or semi-arid regions), thus raising enormous transboundary water management issues. Two countries (Egypt and Sudan) depend almost entirely on the Nile waters, besides some other very unsustainable sources, such as fossil groundwater. Most of those countries' economies rely heavily on agriculture and are facing both increasing demographic trends and water scarcity issues [33,45].

On 22 February 1999, the Nile Basin Initiative (NBI) was established in Dar es Salaam, by ministers responsible for water affairs of nine interested countries (South Sudan was not yet an independent state at that time, and Eritrea is an observer). The NBI is an inter-governmental organization dedicated to equitable and sustainable management and development of the shared water 
resources of the Nile River Basin. The Nile Council of Ministers (Nile-COM) agreed upon a "Strategic Action Program" (SAP) comprised of two complementary programs - the "Shared Vision Program" (SVP) and the "Subsidiary Action Program" (SAP) - to guide Nile cooperation. The shared vision states: "to achieve sustainable socio-economic development through the equitable utilization of and benefit from the common Nile Basin water resources". The SVP is comprised of eight basin-wide projects, with a major focus on building trust, confidence and capacity in member countries, as well as creating an enabling environment for trans-boundary investments [46].

Examples of questions, which could be addressed with the support of DSS in the field of conflict management, are provided in El Fadel et al. [45].

At least two relevant examples of IWRM-DSS developed under the umbrella of the NBI can be cited. A first attempt to build an IWRM-DSS was carried out in 2001-2003 by the Food and Agriculture Organization of the United Nations (FAO), with the financial support of the Italian Government: the Nile River Basin Decision Support Tool (Nile DST) (see [33] for details). A second and larger effort is represented by the "Nile Basin DSS" (NB DSS), funded mainly by the World Bank through the Nile Basin Trust Fund, with the aim of supporting international policies at a strategic level and transboundary planning and management. It includes an information management system and a river basin model connected to a graphical user interface and communication system and supported by a toolkit of analytical tools [47]. The NB DSS was the core component of one of the SVP projects, the Water Resources Planning and Management Project (WRPMP), specifically aimed at enhancing basin-wide analytical capacity to support the development, management and protection of Nile River Basin water resources in an equitable, optimal, integrated and sustainable manner.

It is practically impossible to have a clear perception of the outcomes of these projects and the others cited in this section, without the support of the experts directly involved. Very little information on these projects can be found from a search of the Internet and scientific literature. Moreover, as both DSSs were developed within the same NBI umbrella initiative, it appears that the first tool had only limited impact and applicability, as a new DSS was developed, apparently independently from the first. As the second project ended recently, the NBI Secretariat is currently putting together the formalities (end-user Memorandum of understanding, etc.) to disseminate the DSS to all the riparian countries. A significant number of grey literature documents can be downloaded, but only 10 refereed papers on the two DSSs in the Nile River Basin were found through a search in Scopus (Search: TITLE-ABS-KEY (decision support AND water AND Nile River) AND DOCTYPE (article OR conference paper)) in early 2013, and none with evident links with the NBI projects: another example, which demonstrates the difficulties encountered in analyzing DSS experiences, is the analysis is limited to scientific journals.

According to Guido Santini (FAO), who was involved in the development of the Nile DST, the lack of data needed by the DSS was the main weakness of the project, which could not be implemented successfully. Accessibility to data was also mentioned as a critical issue, as well as software and computer skills. A first lesson learned is therefore that DSS tools should be developed to be user-friendly, flexible and adaptable to local data availability, if they are to find use in decision-making processes. In agreement with most of the other experts, Santini drove the attention for future developments on supporting the decision-making process rather than the developments of technology. 
Thanks to the information provided by A.H. Seid, the NB DSS could be explored in greater details. The NB DSS is an ongoing effort (first release delivered in August 2011), expected to serve primarily in support of water balance quantification and allocation and with the capability to contribute to enhance capacity for basin-wide communication, information sharing and analysis, while carefully considering national needs. The NB DSS design (Figure 3) is based on three major functional components, namely, the information management system (IMS), the river basin modelling system $(\mathrm{RBM})$ and the multi-criteria analysis tools (MCA).

Figure 3. A simplified block diagram showing the relationships between DSS components [48].

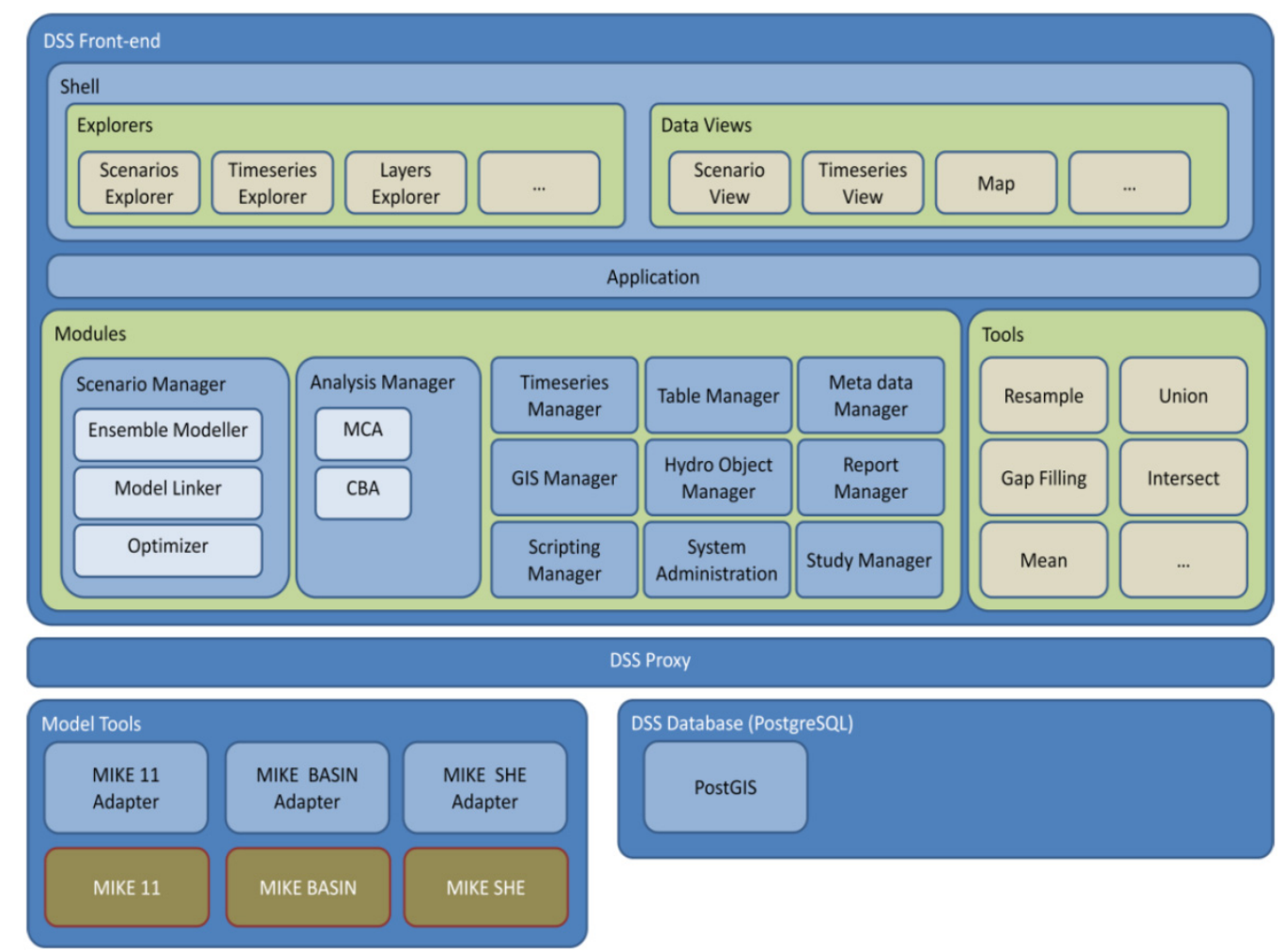

The NB DSS is evidently a very ambitious initiative, which, according to Seid, is facing the common problems related to the quality of available data (in the Nile River Basin, hydro-meteorological data is scarce and often of poor quality). An additional challenge is the uncertainty of future sustainability, which calls for efforts to ensure the required financial and institutional support. Relevant for future sustainability is the long-term perspective (beyond 2012, the date of the project end) of using the NB DSS as a tool for the Water Resources Management Unit (WRMU) at the NBI Secretariat to become a provider of services to other entities and projects, thereby, and thus, having perspectives for becoming financially self-sufficient. According to Sørensen (DHI), it would be important for the NB DSS to become a "center of gravity" for the provision and sharing of data, knowledge and models across borders, so that the long-term perspectives could be met.

The main strengths of the NB DSS are found by Seid in the early involvement and commitment of riparian end-users, its comprehensiveness ("not just another modelling tool"), which include also optimization, benefit-cost analysis and multi-criteria decision tools and its flexibility and capacity to deal with different temporal and spatial scales (e.g., national and transnational). Similarly, Sørensen 
identified "software openness, flexibility and extendibility" as the main strengths of the NB DSS and as assets for long-term sustainability. On the other hand, even if this is considered "the way to go", the trade-off between simplicity and flexibility was pointed out. "Training and organizational ownership" are mentioned as the directions for overcoming the main problems encountered by the project.

\subsection{West Africa (Volta River Basin)}

The Volta River Basin covers around 418,000 $\mathrm{km}^{2}$ encompassing the majority of Burkina Faso and Ghana, but covering also portions of Togo, Benin, Mali and the Ivory Coast. One of the main features of the basin is Lake Volta, created by one of the largest dams in the world, providing water for the most important users located in the basin: agriculture, mining, households and power generation. Increasing population pressure and intensifying agriculture raise the competition for water resources. The climate of the basin is characterized by inter-annual and inter-decadal variability in precipitation.

The Volta River Basin has a rich literature specific on IWRM-DSS (see [8,31,49,50]). All the references mentioned focus on a large long-term project supported by the German Federal Ministry of Education and Research (BMBF) and the German International Cooperation Department and named GLOWA-Volta, a component of the larger international project, GLOWA ("Global Change and the Hydrological Cycle"), focused on several other international river basins. The main scientific objectives of the GLOWA-Volta project are: (i) the analysis of the physical and socio-economic determinants of the hydrologic cycle, in consideration of climate change perspectives; and (ii) the development of a "scientifically sound" DSS for sustainable water resource management [50].

The various references present different aspects of the GLOWA-Volta project, focusing on the use of the coupled hydrological-economic model for groundwater preservation [50], irrigation and cultivation planning [31,49] or sustainable water management in view of climate change scenarios [8]. Unfortunately, all the references consulted share the character of demonstrative applications on selected sub-basins and do not refer to any operational use at the level of the whole transboundary basin.

The modelling system of the GLOWA-Volta project encompasses the use of various modules. In particular, hydrologic simulation is provided by the distributed, deterministic and physically-based Water Balance Simulation Model (WaSiM), while the Economic Irrigation Model is a non-linear mathematical optimization model (GAMS-ECIM) developed with the high-level modelling language GAMS (General Algebraic Modelling System), providing various functionalities, e.g., farmers' income maximization under different scenarios [31] (see Figure 4).

However, an Internet search reveals that also in the case of the Volta River Basin, there is another project dealing with the development of a DSS tool, in this case, aimed specifically at water allocation. Interactions or synergies between the two projects are not evident. The second DSS [51] refers to the grant "Basin Focal Project-Volta", a part of the CGIAR (Consultative Group on International Agricultural Research) Challenge Program on Water and Food. In this case, the modelling system is based on the combination of a spreadsheet calculator for the hydrologic cycle and the software-Water Evaluation and Planning (WEAP) — for water allocation. Interestingly, both projects claim the Volta River Authority as the intended end-user, but we could find no evidence of the use of either one of the two DSS tools by the Authority. 
Figure 4. The structure and main information flows of the GLOWA-Volta model system (adapted from [31]).

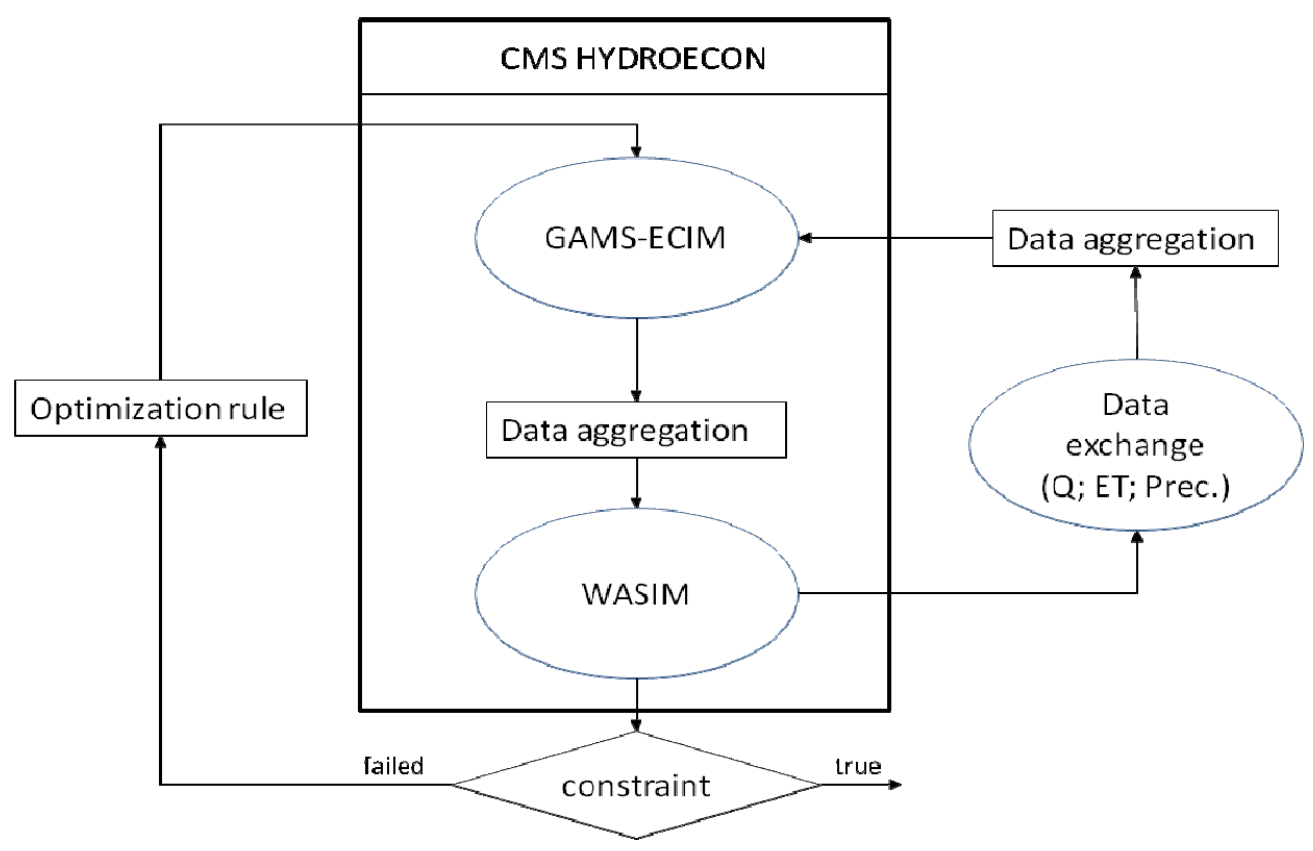

Direct information about DSS development in the Volta River Basin was collected through the questionnaire compiled by Frank Ohene Annor (Civil Engineering Department, Kwame Nkrumah University of Science and Technology, Ouagadougou, Burkina Faso), with reference to four projects: the Water Audit Update in the Volta River Basin (Program for Central and West Africa of International Union for Conservation of Nature), the Challenge Program for Water and Food (CPWF), the Sustainable Management of Water Resources in the Volta Basin (a European Space Agency-TIGER Project) and the GLOWA-Volta Small Reservoirs Project (supported by the German government).

With reference to the various projects listed above, Annor identified their main strengths in the good level of acceptance by riparian countries, which facilitated their involvement in setting the agenda for basin-wide management of water resources. On the other hand, in some cases, data were not readily available and so were computers and other facilities for decision makers at the lower levels for direct use of the DSS tool (in the case of the GLOWA Project).

Motivation of national agencies to be consistent in data collection according to their mandates and to create mechanisms for data harmonization, archiving and sharing and sensitization of government agencies on DSS opportunities are seen as possible directions to improve the current situation. In the medium-/long-term, DSS perspectives in the Volta River Basin, according to Annor, could be significantly enhanced by means of a tool that fosters consultations and negotiations among member countries on shared water resources management.

\subsection{South Africa}

Prasad et al. [36] report that according to the recent National Water Resources Strategy for South Africa, on the average year, the country gets only about half $(450 \mathrm{~mm})$ the world's average rainfall, and it is also affected by remarkable temporal and spatial variations. Such a situation considerably constrains the availability of adequate, reliable and timely water supplies, and droughts and floods are 
both relevant issues in the country. As in many other growing developing economies, the competition for water among human activities and between human activities and the environment is on the rise.

The IWRM literature on South Africa is rather rich (see, for example, [10,28,36,52,53]). The work by Prasad et al. [36] is worth mentioning here, because it proposes a framework for prioritizing water management alternatives by integrating multi-disciplinary approaches by means of multi-criteria decision analysis (MCDA). A graphical presentation of the proposed framework is reported in Figure 5. Other works propose a GIS-based DSS for rainwater harvesting in the upper Orange River Basin [28] and a model-based DSS for a smallholder farming system in the Olifants River Basin, integrating pre-existing models (hydrology, crop production and farm profitability) into a new framework named ICHSEA (Innovative Coupling of Hydrological and Socio-Economic Aspects) [32].

Figure 5. A proposal of a DSS framework for prioritizing water management alternatives by integrating multi-disciplinary approaches by means of multi-criteria decision analysis (MCDA) (adapted from [36]). WM, water management.

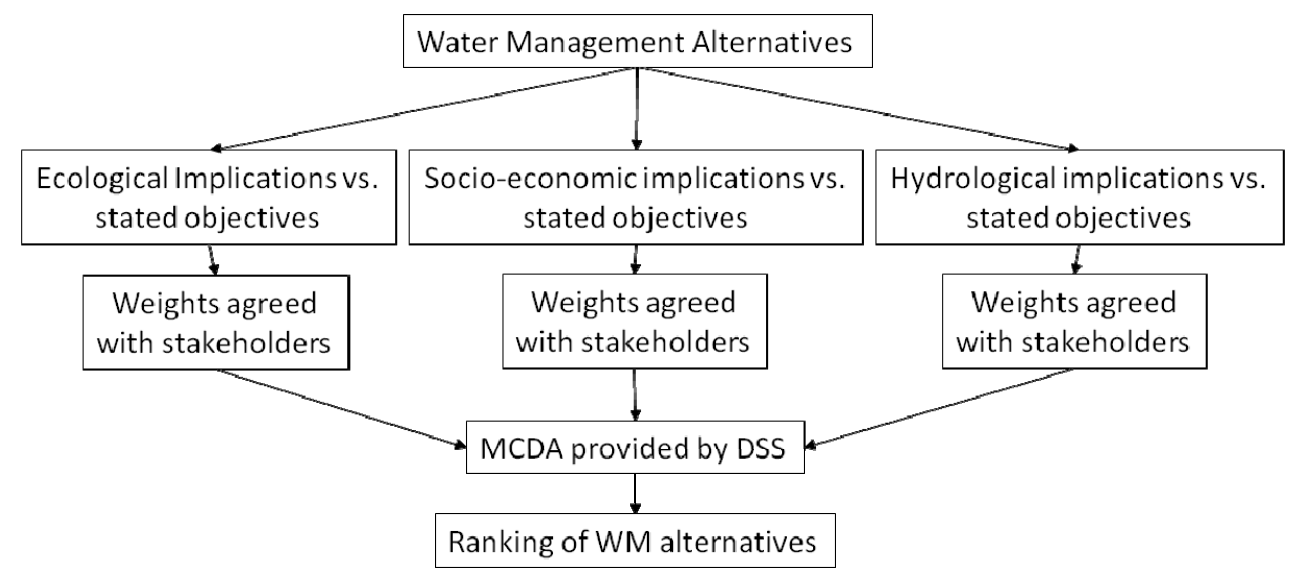

Jean-marc Mwenge Kahinda (Council for Scientific and Industrial Research (CSIR), South Africa) contributed to the survey with reference to the rainwater harvesting DSS supported by the Water Research Commission [28].

The main strengths of the rainwater harvesting DSS are that it is GIS-based and highly customizable, while the main weaknesses are the cost of the required GIS software and its demand of highly skilled professionals. Moreover, data is an issue, due to the coarse resolution of national datasets and the lack of key input data.

In order to overcome these problems, the DSS could be integrated into free GIS software. Investments on new and improved (higher resolution) comprehensive maps for South Africa and, in the medium-term, the inclusion of climate change scenarios, are also seen as improvements that would enable the tool to become more relevant for policy makers.

\section{Discussion and Conclusions}

The survey demonstrated that in all the cases examined, PP, SM and DA methodologies were playing important roles in the IWRM-DSS approaches implemented in Africa, thus confirming that they should also be considered as fundamental components in future efforts. The analysis of the cases 
and the interactions with the experts did not result in a specific list of wrong and right actions or components for future DSS development. Nevertheless, the strengths and weaknesses, which have emerged from the cases, allow identification of the main directions of the required improvements.

Several efforts could contribute to increasing the potentials of IWRM-DSS in developing countries and elsewhere. First of all, the overall framework should be considered. In this regard, it is critical that commonalities in the requirements of potential DSS end-users drive the identification of "typical" needs and application contexts and the related methodological and technical solutions (i.e., DSS modules). Protocols and standards for technology integration and interoperability could significantly contribute toward this direction and so could the support for technology transfer and for the development of IWRM-DSS from prototypes to operational tools. Similarly, exchanges of experiences (and tools/modules) should be fostered, such as twinning activities supported in recent times by European Framework Programs for Research. These could include north-south, but also south-south twinning of river basin authorities and related case-studies for sharing experiences and identifying guidelines for effective adaptation of existing DSS frameworks, in particular to developing countries. In general, the analysis of the literature, of the implementation cases and of the interactions with the experts clarified that the quality of the tools per se cannot guarantee the quality of the process. The IWRM-DSS should therefore be structured within methodological frameworks in which all the phases and components of the policy/decision-making process are considered, as proposed in Figure 1. Moreover, tools should be supported by adequate cultural background: Jean-marc Mwenge Kahinda (CSIR South Africa) reported that "The concept of IWRM is dying a slow death in Africa". He added also that the main constraints to wider use of IWRM-DSS are in the fact that "Few government officials understand IWRM".

The survey also provides information on the outcomes concerning participation and, more broadly, the human dimension. It is evident in this regard that the quality of the DSS results is determined by the quality of the management of the decision processes. Similarly, the usefulness of the outcomes depends on the quality of the communication and training strategies. Experience shows that there is not a single recipe for the success of DSS developments, but many necessary ingredients related to participation are known, such as the early involvement of end-users and the flexibility of the tools in considering their needs. The exact dosage (quantity and quality) is, to a large extent, context-dependent: what has worked in one context is no definite guarantee for success in a different context. Nevertheless, we believe that with the contribution of the present work, disseminating knowledge on recent experiences in DSS developments and applications in the water management field can lead to the definition of a set of guidelines that can be considered valid in general and help avoid past mistakes, knowing very well that they should be significantly tailored and adapted case-by-case.

In accordance with the outcomes of the questionnaires, ongoing and future efforts for IWRM-DSS development should carefully consider the main constraints identified so far. According to Seid (NBI), consideration should be given in particular to the "Lack of enabling policy environment: decision support systems can be effectively used if there is a policy regime that promotes a participatory and transparent decision-making process. Though, theoretically, adopting IWRM principles amounts to accepting to promote a participatory and transparent decision-making process, in practice, developing countries need to do a lot more to implement such a decision-making process, thereby paving the way for effective application of decision support systems". Going beyond participation, but still with regard 
to the human dimension, solutions should be found for the "Lack of adequate capacity; lack of trained technical personnel is another constraint in many of the developing countries".

In addition, on the topic of participation, Matthew McCartney (IWMI, Battaramulla, Sri Lanka) pointed out that one of the most urgent need for future research is the "development of simple cost-effective DSS that facilitate stakeholder involvement". Another relevant issue is "whether DSSs answer the questions that decision-makers want answers to in a timely manner. Often, these questions are related to water, but this may not be explicit...DSSs need to be able to answer these questions, and often, despite all their complexity, they cannot. They also tend to answer questions in a way that is not necessarily easily understood and a long time after the question needs to be answered".

Thirdly, and in many cases, most importantly, the scientific and information bases of the analytical tools and, in particular, those of simulation models implemented in the DSS tools should be considered. In this regard, Abdulkarim Seid (Nile Basin Initiative, Addis Ababa, Ethiopia) drove the attention in particular on "Shortage of relevant data: in many developing countries (many of the Nile riparians fall in this), there is a shortage of data that would be needed to exploit full potentials of decision support systems" and on "Inadequate research in understanding the water resources system, in particular, how various alternatives of water resource development and management alternatives affect the ecological and socio-economic subsystems of a river basin". Moreover, Boroto (FAO-RAF) remarked that "ICT infrastructure and capabilities [are] a key component in DSS. When such a tool depends on "real-time" data, the ICT infrastructure becomes a limitation" and this is a common problem in many African regions. Seid suggested that the future research has to contribute to "establish the relationship between how changes in hydrologic regimes affect the ecological and socio-economic sub-systems of the river basin. Such research would help in developing causal relationship for translating changes in the hydrologic regime as a result of contemplated water resource development and management interventions into environmental and socio-economic impacts. Such relationships can then be implemented in the IWRM-DSS and used to make decisions, taking into account environmental, social and economic criteria...DSS development should be accompanied by practical applications - thereby demonstrating the value of the DSS in addressing the concerns of stakeholders".

Finally, concerning the DSS components more specifically focused on decision-making (DA), Annor (Kwame Nkrumah University, Ouagadougou, Burkina Faso) stated in the questionnaire that IWRM-DSS in developing countries can be "Key to the management of the resources with minimum conflict". Sørensen (DHI, Copenhagen, Denmark) added that "Scientifically acceptable approaches are obviously needed, and transparent DSS approaches, such as CBA and MCA, optimization and uncertainty/risk assessments should be there in some form (hence, DSS should clearly be more than "just" modelling). The critical issues are, however, more related to end-user ownership and perceived usefulness and the ability to use the system (training and ability to retain resources including staff, as well as funding)". He added also that "One of the most critical elements for success (in the long-term) is the organizational setup and ownership. The technologies may be perfect, but if the organization aspects, future funding mechanisms, etc., are not in place, then most projects will fail...I believe that the technology is not really the most critical issue".

In summary, from the outcomes of the survey, it appears that recent developments in the field of IWRM-DSS considered all the disciplinary components; the methodological issues related to their 
integration and framing within decision/policy-making processes, as proposed above, and workable solutions were made available. Nevertheless, a series of problems and limitations were identified, which seriously hinder the potential of decision support tools for contributing to IWRM in Africa and elsewhere.

What could be the contributions of the Splash Project and, more generally, of coordinated European funding agencies towards improving the current situation for the promotion, application and enhancement of DSS in IWRM policy-making?

A very concrete set of options emerged from the analyses conducted herein, which should be considered in future efforts in the field:

(1) Let everybody benefit from the big and most favored ones: a jointly funded activity with a transnational approach to establish a permanent forum for exchanging experiences in DSS development and implementation in Africa, with the main references to be found, first of all, in the Nile and Volta River basins.

(2) Knowing who is around and exploiting others' experiences: development of a knowledge base about recent and ongoing efforts in the field of IWRM-DSS tools, to avoid duplication of efforts and facilitate exchanges and synergies.

(3) Training and motivating the main actors of IWRM in Africa: north-south and south-south training and capacity building activities aimed at facilitating the transfer of skills and experiences amongst the main transnational river basins.

(4) Towards a continental data infrastructure for IWRM: establish an expert group with the support and participation of the most important international donors [FAO, the World Bank (WB), CGIAR, the EU Commission, etc.] for the development of a joint strategy on data: standards, repositories, maintenance, etc. This should be squarely set within national statistical frameworks, so as to ensure reliability, consistency and sustainability. In this regard, the application of the System of Environmental-Economic Accounting [54], for which water accounts have been identified as a priority, should be supported.

\section{Acknowledgments}

The authors gratefully acknowledge the financial support of the Splash Project financed by the European Commission, ERA-NET Program and the contribution of many distinguished experts and, in particular, those who provided their experiences and views through the compilation of the questionnaires: Miriam Feilberg, Manfred Kaufmann and Olivier Cogels (SPLASH Project); Jean Boroto (FAO-RAF); Guido Santini (FAO); Abdulkarim H. Seid (NBI); Henrik R. Sørensen (DHI); Frank Ohene Annor (Kwame Nkrumah University); Jean Marc Mwenge Kahinda (CSIR); and Matthew McCartney and Parvaneh Honarmand (IWMI). A grateful thank you goes also to the many colleagues who contributed to the development of the NetSyMoD approach over the last decade and, in particular, to Jaroslav Mysiak (FEEM). 


\section{References}

1. Holling, C.S.; Gunderson, L.H.; Peterson, G.D. Sustainability and Panarchies. In Panarchy: Understanding Transformations in Human and Ecological Systems; Gunderson, L.H., Holling, C.S., Eds.; Island Press: Washington, DC, USA; London, UK, 2002; pp. 63-102.

2. Rittel, H.W.J.; Webber, M.M. Dilemmas in a general theory of planning. Policy Sci. 1973, 4, 155-169.

3. Qi, H.; Altinakar, M.S. A conceptual framework of agricultural land use planning with BMP for integrated watershed management. J. Environ. Manag. 2011, 92, 149-155.

4. Geertman, S.; Stillwell, J. Planning Support Systems Best Practice and New Methods; Springer: Dordrecht, The Netherlands, 2009.

5. Giupponi, C.; Mysiak, J.; Depietri, Y.; Tamaro, M. Decision Support Systems for Water Resources Management: Current State and Guidelines for Tool Development. In Decision Support for Water Framework Directive Implementation; Vanrolleghem, P.A., Ed.; IWA Publishing: London, UK, 2011; pp. 107-202.

6. Giupponi, C.; Sgobbi, A. Models and Decision Support Systems for Participatory Decision-making in Integrated Water Resource Management. In Coping with Water Deficiency. From Research to Policy Making; Koundouri, P., Ed.; Springer: Dordrecht, The Netherlands, 2007; Volume 48, pp. 165-186.

7. Coelho, A.C.; Labadie, J.W.; Fontane, D.G. Multicriteria decision support system for regionalization of integrated water resources management. Water Resour. Manag. 2012, 26, 1325-1346.

8. Kunstmann, H.; Jung, G.; Wagner, S.; Clottey, H. Integration of atmospheric sciences and hydrology for the development of decision support systems in sustainable water management. Phys. Chem. Earth 2008, 33, 165-174.

9. Le Page, M.; Berjamy, B.; Fakir, Y.; Bourgin, F.; Jarlan, L.; Abourida, A.; Benrhanem, M.; Jacob, G.; Huber, M.; Sghrer, F.; et al. An integrated DSS for groundwater management based on remote sensing. The case of a semi-arid aquifer in Morocco. Water Resour. Manag. 2012, 26, 3209-3230.

10. Prasad, K.C.; Strzepek, K.M.; van Koppen, B. An approach to assessing socioeconomic implications of water management alternatives. Water Policy 2007, 9, 131-147.

11. Qi, H.; Altinakar, M.S. Integrated watershed management with multi-objective land use optimizations under uncertainty. J. Irrig. Drain. Eng. 2013, 139, 239-245.

12. Siebenhuner, B.; Barth, V. The role of computer modelling in participatory integrated assessments. Environ. Impact Assess. Rev. 2005, 25, 367-389.

13. Morrison, M.; Morgan, M.S. Models as Mediating Instruments. In Models as Mediators: Perspective on Natural and Social Sciences; Morgan, M.S., Morrison, M., Eds.; Cambridge University Press: Cambridge, UK, 1999; pp. 10-37.

14. Pielke, J.R.A. The Role of Models in Prediction for Decision. In Understanding Ecosystems: The Role of Quantitative Models in Observations, Synthesis, and Prediction; Canham, C., Lauenroth, W., Eds.; Princeton University Press: Princeton, NJ, USA, 2003; pp. 113-137. 
15. Doyle, J.K.; Ford, D.N. Mental models concepts for system dynamics research. Syst. Dyn. Rev. 1998, 14, 3-29.

16. Pimbert, M.P. Institutionalising Participation and People-Centred Processes in Natural Resource Management: Research and Publications Highlights; International Institute for Environment and Development (IIED) and Institute for Development Studies (IDS), University of Sussex: Brighton, UK, 2004.

17. Reed, M.S. Stakeholder participation for environmental management: A literature review. Biol. Conserv. 2008, 141, 2417-2431.

18. Huang, I.; Keisler, J.; Linkov, I. Multi-crietria decision analysis in environmental sciences: Ten years of applications and trends. Sci. Total Environ. 2011, 409, 78-94.

19. Argent, R.M.; Voinov, A.; Maxwell, T.; Cuddy, S.M.; Rahman, J.M.; Seaton, S.; Vertessy, R.A.; Braddock, R.D. Comparing modelling frameworks-A workshop approach. Environ. Model. Softw. 2006, 21, 895-910.

20. Byrne, J.; Davies, G. Participation and the NSW Policy Process: A Discussion Paper for the Cabinet Office New Sough Wales; New South Wales Cabinet Office: Sidney, Australia, 1998.

21. Belton, V.; Stewart, T.J. Multiple Criteria Decision Analysis: An Integrated Approach; Kluwer Academic Publishers: Boston, MA, USA; Dodrecht, The Netherlands; London, UK, 2002.

22. Berthoz, A. La décision; Odile Jacob: Paris, France, 2003.

23. Raiffa, H. Decision Analysis: Introductory Readings on Choices Under Uncertainty; McGraw Hill: New York, NY, USA, 1997.

24. Smith, P.D.; McDonough, M.H. Beyond public participation: Fairness in natural resource decision-making. Soc. Nat. Resour. 2001, 14, 239-241.

25. Ryan, M. The role of social process in participative decision-making in an international context. Particip. Empower. Intern. J. 1999, 7, 33-42.

26. McIntosh, B.S.; Giupponi, C.; Voinovc, A.; Smith, C.; Matthewse, K.B.; Monticino, M.; Kolkman, M.J.; Crossman, N.; Ittersum, M.V.; Haase, D.; et al. Bridging the Gaps between Design and Use: Developing Tools to Support Environmental Management and Policy. In State of the Art and Futures in Environmental Modelling and Software; Jakeman, T., Rizzoli, A., Voinov, A., Chen, S.H., Eds.; Elsevier: Amsterdam, The Netherlands, 2009; pp. 33-48.

27. Swyngedouw, E.; Page, B.; Kaika, M. Achieving Participatory Governance: Sustainability and Policy Innovation in a Multi-Level Context. Cross-Cutting Issues in the Water Sector; Working Papers in Employment, Work and Finance; WPG 02-13; School of Geopgraphy and the Environment, University of Oxford, Oxford, UK, 2002.

28. Mwenge Kahinda, J.; Taigbenu, A.E.; Sejamoholo, B.B.P.; Lillie, E.S.B.; Boroto, R.J. A GIS-based decision support system for rainwater harvesting (RHADESS). Phys. Chem. Earth 2009, 34, 767-775.

29. Letcher, R.A.; Croke, B.F.W.; Jakeman, A.J.; Merritt, W.S. An integrated modelling toolbox for water resources assessment and management in highland catchments: Model description. Agric. Syst. 2006, 89, 106-131.

30. Hare, M. Modellers' Recommended Research Directions for Models to Support the Participatory Elements of the Water Framework Directive; Harmoni-CA Project: Brussels, Belgium, 2004. 
31. Ahrends, H.; Mast, M.; Rodgers, C.; Kunstmann, H. Coupled hydrological-economic modelling for optimised irrigated cultivation in a semi-arid catchment of West Africa. Environ. Model. Softw. 2008, 23, 385-395.

32. Magombeyi, M.S.; Taigbenu, A.E. An integrated modelling framework to aid smallholder farming system management in the Olifants River Basin, South Africa. Phys. Chem. Earth 2011, $36,1012-1024$.

33. Georgakakos, A.P. Decision Support Systems for Integrated Water Resources Management with an Application to the Nile Basin. In Topics on System Analysis and Integrated Water Resources Management; Castelletti, A., Soncini-Sessa, R., Eds.; Elsevier: Amsterdam, The Netherlands, 2007; pp. 99-116.

34. Hadded, R.; Nouiri, I.; Alshihabi, O.; Massmann, J.; Huber, M.; Laghouane, A.; Yahiaoui, H.; Tarhouni, J. A decision support system to manage the groundwater of the zeuss koutine aquifer using the WEAP-MODFLOW framework. Water Resour. Manag. 2013, 27, 1-20.

35. Mysiak, J.; Giupponi, C.; Rosato, P. Towards the development of a decision support system for water resource management. Environ. Model. Softw. 2005, 20, 203-214.

36. Prasad, K.C.; Strzepek, K.M.; van Koppen, B. Addressing Socioeconomic Objectives through Enhanced Decision Support Systems for Water Resources Management: Vision, Gaps, and Challenges in South Africa. In Proceedings of International Conference on Politics and Information Systems, Technologies and Applications (PISTA), Orlando, FL, USA, 21-25 July 2004; pp. 182-187.

37. McDonnell, R.A. Challenges for integrated water resources management: How do we provide the knowledge to support truly integrated thinking? Int. J. Water Resour. Dev. 2008, 24, 131-143.

38. SPLASH, Coordinating European Water Research for Poverty Reduction. Available online: http://www.splash-era.net/ (accessed on 23 May 2013).

39. UN Agenda 21; United Nations: New York, NY, USA, 1992.

40. Harmancioglu, N.; Barbaros, F.; Cetinkaya, C. Sustainability issues in water management. Water Resour. Manag. 2012, 26, 1-25.

41. Dalal-Clayton, D.B.; Bass, S. Sustainable Development Strategies: A Reference Book; Earthscan Publications: London, UK, 2002.

42. Hailey, J. Beyond the Fomulaic: Process and Practice in Sough Asian NGOs. In Participation: The New Tyranny?; Cooke, B., Kothar, U., Eds.; Zed Books: London, UK, 2001; pp. 88-101.

43. Scopus Document Search Home Page. Available online: http://www.scopus.com/home.url (accessed on 23 May 2013).

44. Data Synthesis System for World Water Resources Home Page. Available online: http://www.wwap-dss.sr.unh.edu/index.html (accessed on 23 May 2013).

45. El-Fadel, M.; El-Sayegh, Y.; El-Fadl, K.; Khorbotly, D. The Nile River Basin: A case study in surface water conflict resolution. J. Nat. Resour. Life Sci. Educ. 2003, 32, 107-117.

46. Nile Basin Initiative Home Page. Available online: http://www.nilebasin.org/newsite/ (accessed on 23 May 2013).

47. Water Resource Planning and Management Project Home Page. Available online: http://wrpmp.nilebasin.org/ (accessed on 23 May 2013).

48. Seid, A.H. Nile Basin Initiative, Personal communication, Addis Ababa, Ethiopia, 2013. 
49. Bharati, L.; Rodgers, C.; Erdenberger, T.; Plotnikova, M.; Shumilov, S.; Vlek, P.; Martin, N. Integration of economic and hydrologic models: Exploring conjunctive irrigation water use strategies in the Volta Basin. Agric. Water Manag. 2008, 95, 925-936.

50. Rodgers, C.; van de Giesen, N.; Laube, W.; Vlek, P.; Youkhana, E. The GLOWA volta project: A framework for water resources decision-making and scientific capacity building in a transnational West African Basin. Water Resour. Manag. 2007, 21, 295-313.

51. De Condappa, D.; Chaponnière, A.; Lemoalle, J. Decision-Support Tool for Water Allocation in the Volta Basin. Volta Basin Focal Project Report No. 10; IRD and CPWF: Montpellier, France; Colombo, Sri Lanka, 2008.

52. Birendra, K.C.; Schultz, B.; Prasad, K. Water management to meet present and future food demand. Irrig. Drain. 2011, 60, 348-359.

53. Prasad, K.C.; van Koppen, B.; Strzepek, K. Equity and productivity assessments in the Olifants River basin, South Africa. Nat. Resour. Forum 2006, 30, 63-75.

54. United Nations Department of Economic and Social Affairs, Statistics Division Home Page. Available online: https://unstats.un.org/unsd/envaccounting/water.asp (accessed on 23 May 2013).

(C) 2013 by the authors; licensee MDPI, Basel, Switzerland. This article is an open access article distributed under the terms and conditions of the Creative Commons Attribution license (http://creativecommons.org/licenses/by/3.0/). 